Q

Check for

updates

Cite as

Nano-Micro Lett.

(2021) 13:187

Published online: 4 September 2021 (C) The Author(s) 2021

\section{Correction to: Prussian Blue Analogues in Aqueous Batteries and Desalination Batteries}

\author{
Chiwei Xu ${ }^{1}$, Zhengwei Yang ${ }^{1}$, Xikun Zhang ${ }^{1}$, Maoting Xia ${ }^{1}$, Huihui Yan ${ }^{1}$, Jing Li ${ }^{1}$, \\ Haoxiang Yu' ${ }^{1}$, Liyuan Zhang ${ }^{1}$, Jie Shu ${ }^{1} \bowtie$
}

The original article can be found online at https://doi.org/10.1007/s40820-021-00700-9.

Chiwei $\mathrm{Xu}$ and Zhengwei Yang have contributed equally to this work.

$\triangle$ JieShu, shujie@nbu.edu.cn

1 School of Materials Science and Chemical Engineering, Ningbo University, Ningbo, Zhejiang 315211, People's Republic of China

Correction to: Nano-Micro Lett. (2021) 13: 166

https://doi.org/10.1007/s40820-021-00700-9

In the published article the authors equal contribution statement is incorrect in the foot note. The correct statement should be read as "Chiwei Xu and Zhengwei Yang have contributed equally to this work".

Open Access This article is licensed under a Creative Commons Attribution 4.0 International License, which permits use, sharing, adaptation, distribution and reproduction in any medium or format, as long as you give appropriate credit to the original author(s) and the source, provide a link to the Creative Commons licence, and indicate if changes were made. The images or other third party material in this article are included in the article's Creative Commons licence, unless indicated otherwise in a credit line to the material. If material is not included in the article's Creative Commons licence and your intended use is not permitted by statutory regulation or exceeds the permitted use, you will need to obtain permission directly from the copyright holder. To view a copy of this licence, visit http://creativecommons.org/licenses/by/4.0/. 